Review

\title{
“Algae’s sulfated polysaccharides modifications: Potential use of microbial enzymes"
}

\author{
Daniela de Borba Gurpilhares ${ }^{\mathrm{a}, *}$, Tatiane Rodrigues Moreira ${ }^{\mathrm{a}}$, Julia da Luz Bueno ${ }^{\mathrm{a}}$, \\ Leonardo Paes Cinelli ${ }^{\mathrm{a}, \mathrm{b}}$, Priscila Gava Mazzola ${ }^{\mathrm{c}}$, Adalberto Pessoa ${ }^{\mathrm{e}}$, Lara Durães Sette ${ }^{\mathrm{d}}$ \\ a Faculdade de Farmácia, Universidade Federal do Rio de Janeiro, Av. Aluizio da Silva Gomes, 50, Granja dos Cavaleiros, 27930-560, Macaé, RJ, Brazil \\ ${ }^{\mathrm{b}}$ Grupo de Glicofármacos-Laboratório Integrado de Prospecção em Produtos Bioativos, Faculdade de Farmácia, Universidade Federal do Rio de Janeiro, Av. \\ Aluizio da Silva Gomes, 50, Granja dos Cavaleiros, 27930-560, Macaé, RJ, Brazil \\ c Faculdade de Ciências Farmacêuticas, Universidade de Campinas-UNICAMP, Sérgio Buarque de Holanda, 250, Piso II, E06, 13083-859 Campinas, SP, \\ Brazil/Departamento de Patologia Clinica, Faculdade de Ciências Médicas, Universidade de Campinas-UNICAMP, R. Alexander Fleming, 105, Bloco FCM 12, \\ 13083-881, Campinas, SP, Brazil \\ ${ }^{\mathrm{d}}$ Departamento de Bioquímica e Microbiologia, Instituto de Biociências, Universidade Estadual Paulista Júlio de Mesquita Filho-UNESP, Av. 24A, 1515, Bela \\ Vista, 13506-900, Rio Claro, SP, Brazil \\ e Departamento de Tecnologia Bioquímico-Farmacêutica, Escola de Ciências Farmacêuticas, Universidade de São Paulo, Av. Prof. Lineu Prestes, 580, Bloco \\ 16, 05508-900, São Paulo, SP, Brazil
}

\section{A R T I C L E I N F O}

\section{Article history:}

Received 10 December 2015

Received in revised form 29 March 2016

Accepted 20 April 2016

Available online 21 April 2016

\section{Keywords:}

Biological activity

Hydrolases

Lyases

Marine algae

Microorganisms

Sulfatases

Sulfotransferases

\begin{abstract}
A B S T R A C T
Marine algae are valuable sources of structurally diverse bioactive compounds, among them, the group of sulfated polysaccharides (SPs). As an example of SPs, it could be cited the fucoidans in brown algae, carrageenans in red algae and ulvans in green algae. Since the past decades, SPs have been extracted from algae and evaluated in respect to their beneficial biological activities such as anti-inflammatory, antioxidative, antimicrobial, anticoagulant, antithrombotic, immunological and anticancer. This review deals with the presentation of natively bioactive SPs structural features in addition to already employed approaches of SPs structure modifications, such as chemical and physical methods. Moreover, this article presents the advantages and the importance of using enzymatic methods during SPs modification, and particularly, the use of microorganisms as enzymes sources. Enzymes such as hydrolases/glycosidases (e.g. fucoidanase, fucosidase, agarase and carrageenase), lyases, sulfotransferases and sulfatases could be used for this purpose. It has been shown that more studies are necessary to obtain/identify opportunities to create novel, or to intensify, SPs biological properties. Considering the advantages in the use of microbial enzymes in biotransformation processes, studies related to the modification of SPs by microorganisms should be stimulated.
\end{abstract}

(c) 2016 Elsevier Ltd. All rights reserved.

\section{Contents}

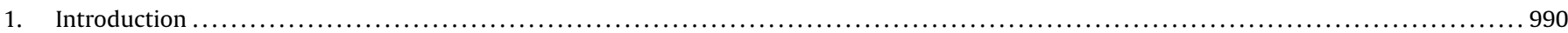

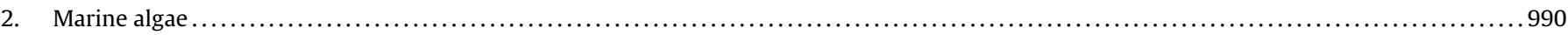

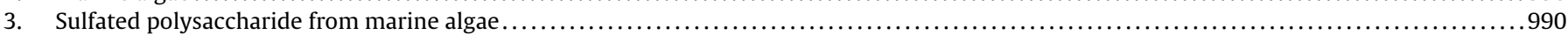

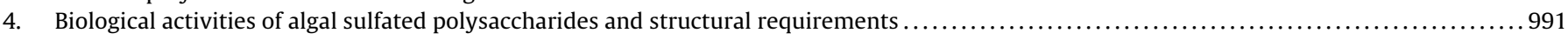

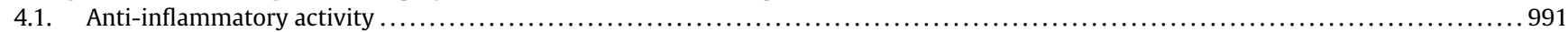

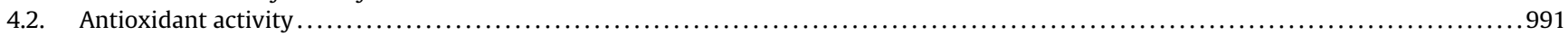

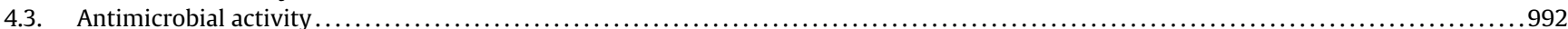

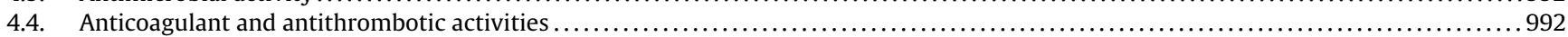

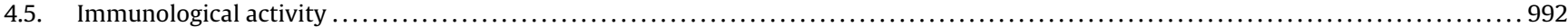

\footnotetext{
* Corresponding author.

E-mail addresses: gurpibunch@uol.com.br, danielagurpi@macae.ufrj.br (D.d.B. Gurpilhares).
} 


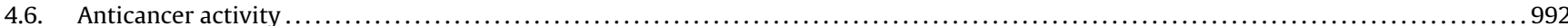

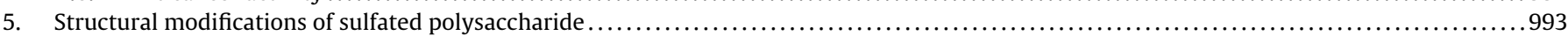

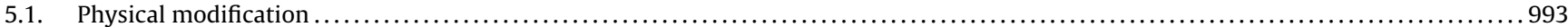

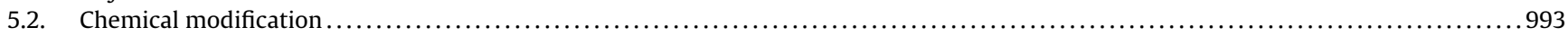

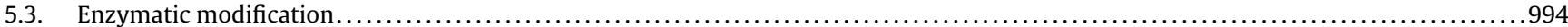

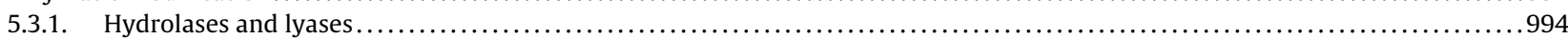

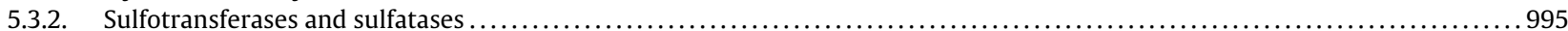

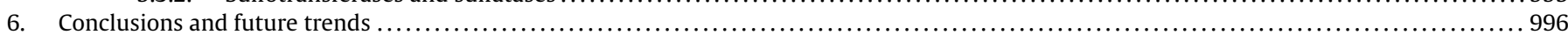

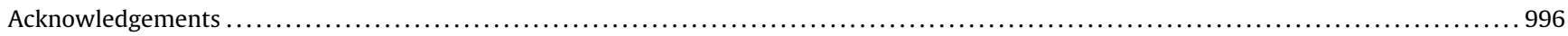

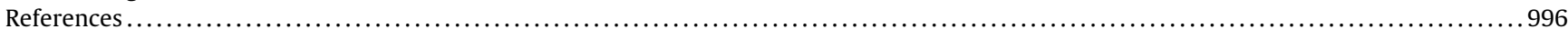

\section{Introduction}

Sulfated polysaccharides (SPs) are one group of the most interesting and attractive components of marine algae cell walls. They are a class of compounds with hemi-ester sulfate groups on a polysaccharide backbone [1]. Based on the algae classification, red, green or brown, polysaccharides may vary accordingly to the more abundant monosaccharide (carbohydrate structure), molecular weight, degree of sulfate esterification, the linking position of glycosidic bonds, sulpho groups and other substituents [2]. Fucoidans, sulfated fucans and laminarans are commonly reported in brown algae, while carrageenans and sulfated galactans in red algae, ulvans and sulfated heteropolysaccharides in green [3].

Despite the focus of SPs in food industry applications, in recent years, attention has shifted to the exploitation of potential biological activities and pharmacological properties [4]. Therefore, studies that aim to evaluate the importance of polysaccharide structures over bioactivity are crucial. Anticoagulation, antiviral, anti-tumor, anti-inflammatory and antioxidant are some biological activities already studied. However, relatively few studies have interpreted the biological activity of SPs (e.g. fucoidans, sulfated fucans and sulfated galactans) in terms of molecular structure [5].

Structural elucidation of algal polysaccharides is needed to correlate their physico-chemical or biological properties. Furthermore, the analysis of distinct structural features may lead to the improvement of beneficial properties by specific modifications (chemical, physical or enzymatic). Prior to structural modifications, structural analysis is required in addition to a whole set of modern analytical procedures, sometimes together with specific additional methods, as those for purification steps, for example [6].

Considering that biological activities depend on the molecular structure, we have to take a careful look of the poly and oligosaccharide structure and strategies have to be developed to produce pure oligosaccharides [7].

Recent insights into the structures of some algal polysaccharides may help to explain their activity mode, which depend on the use of enzymes degrading polysaccharides [8]. Nevertheless, only a few studies regarding the isolation and characterization of enzymes used in sulfated polysaccharides modification have been performed.

Since microorganisms are potential producers of enzymes with biotechnological interest, the screening and identification of them also remains a challenge.

This review aims to give an up-to-date view of the general structural properties of SPs from marine algae and to present a discussion of the employed methods for polysaccharides modifications, focusing on specific microbial enzymes, which are expected to simplify structural and structure/function studies.

\section{Marine algae}

The world's surface is covered by oceans in more than $70 \%$. In this sense, the wide diversity of marine organisms could be a rich source of natural products. Among those organisms, marine algae present diverse bioactive compounds with various biological activities [9].

The term "algae" refers to a complex association of photosynthetic organisms with different origin and evolutionary history. In a practical manner, algae could be separate into two groups: 1) multicellular marine organisms (macrophytes, seaweeds) and 2) unicellular or colonial microalgae that inhabit not only oceans, but fresh water lakes, rivers, ponds and soil [6].

Seaweeds are macroalgae that can be represented by red (Rodophyta), brown (Phaeophyceae) and green(Chlorophyta) algae [6].

During the last decades, seaweeds have been studied because of their composition, which correspond to their edible characteristics and other commercial purposes, such as their pharmaceutical properties [4]. The bioactive compounds of marine algae include polyphenols, polysaccharides [10], proteins, lipids, vitamins and minerals [11]. The total concentration of components, in dry weight, will depend on the algae type and growth conditions: polysaccharides can range from 4 to $76 \%$, protein content in green and red algae vary from 10 to $30 \%$ in comparison to $5-15 \%$ of brown algae, lipids can account for $1-5 \%$ of cell composition (major classes: phospholipids and glycolipids). Other important chemical groups are phenolic and mineral compounds, that vary qualitatively and quantitatively [11].

Marine algae have attracted a special interest because of their richness in sulfated polysaccharide [9].

\section{Sulfated polysaccharide from marine algae}

Sulfated polysaccharides, SPs, are complex macromolecules with broad spectrum of activity as a function of a chemical structure rich in polyanions, which allows its connection to a large number of proteins in solution (cell matrix or blood plasma) [12]. These structures have a wide distribution in nature, being found in microorganisms, seaweeds, vertebrates and invertebrates [13]. In fact, a great amount of SPs seaweed with biological properties was so far investigated, showing complex and heterogeneous structures [14].

The major constituent (sugar) in red algae is galactose, being designated as galactans [14]. Carrageenans and agar (galactans) are the main SPs produced by red seaweeds (Rhodophyta) [11].

In green algae (Chlorophyta), the major polysaccharides are, in turn, polydisperse heteropolysaccharides where glucuronoxylorhamnans, glucuronoxylorhamnogalactans or xyloarabinogalactans are the three main groups, whereas alginate is mainly found in brown seaweeds (Phaeophyceae) [11]. Studies of alginates indicate that their constitution is based on the existence of two different uronic acid residues in blocks of homopolymeric sequences of either D-mannuronic acid residues (M-blocks) and/or L-guluronic acid residues (G-blocks), separated by long sequences of heteropolymeric material (MG-blocks) [15]. Furthermore, fucans include, among others, compounds such as fucoidin, fucoidan, sargassan, which are SPs that can also be found in brown seaweeds, 
Table 1

Types of sulfated polysaccharide found in marine algae.

\begin{tabular}{|c|c|c|c|}
\hline Polymer & Algae species & Alga & Reference \\
\hline Fucans & Laminaria digitata, Pelvetia canaliculata, Fucus vesiculosus, Sargassum muticum and Ascophyllum nodosum & Brown & (Grauffel et al.) [16] \\
\hline Carrageenan & Solieria chordalis & Red & (Bondu et al.) [17] \\
\hline Fucoidan & Fucus evanescens & Brown & (Anastyuk et al.) [18] \\
\hline Kappa-carrageenan & Hypnea musciformis & Red & (Arman and Qader) [19] \\
\hline Carrageenan & Chondracanthus chamissoi & Red & (Wang et al.) [20] \\
\hline Agarose & Gloiopeltis furcata & Red & (Hu et al.) [21] \\
\hline Fucan & Sargassum vulgare & Brown & (Dore et al.) [22] \\
\hline Laminaran & Eisenia bicyclis & Brown & (Menshova et al.) [23] \\
\hline Fucoidan & Saccharina gurjanovae & Brown & (Shevchenko et al.) [24] \\
\hline Aginates & Cystoseira trinode, Cystoseira myrica, Sargassum dentifolium, Sargassum asperifolium Sargassum latifolium & Brown & (Larsen et al.) 15] \\
\hline Galactan & Gelidium crinale & Red & (Pereira et al.) [14] \\
\hline Alginate & Sargassum fusidorme & Brown & (Cong et al.) [25] \\
\hline Laminarans and fucoidans & Alaria fistulosa, A. marginata, Laminaria cichorioides Fucus evanescens & Brown & (Zvyagintseva et al.) [26] \\
\hline Carrageenan & Hypnea musciformis & Red & (Ghannam et al.) [27] \\
\hline Xylofucoglucuronan & Spatoglossum schroëderi & Brown & (Leite et al.) [28] \\
\hline Agar, carrageenan & Osmundea pinnatifida, Grateloupia turuturu, Gracilaria gracilis & Red & (Rodrigues et al.) [11] \\
\hline Alginates, fucoidans & Sargassum muticum, Saccorhiza polyschides & Brown & {$[11]$} \\
\hline Galactomannans & Codium tomentosum & Green & [11] \\
\hline
\end{tabular}

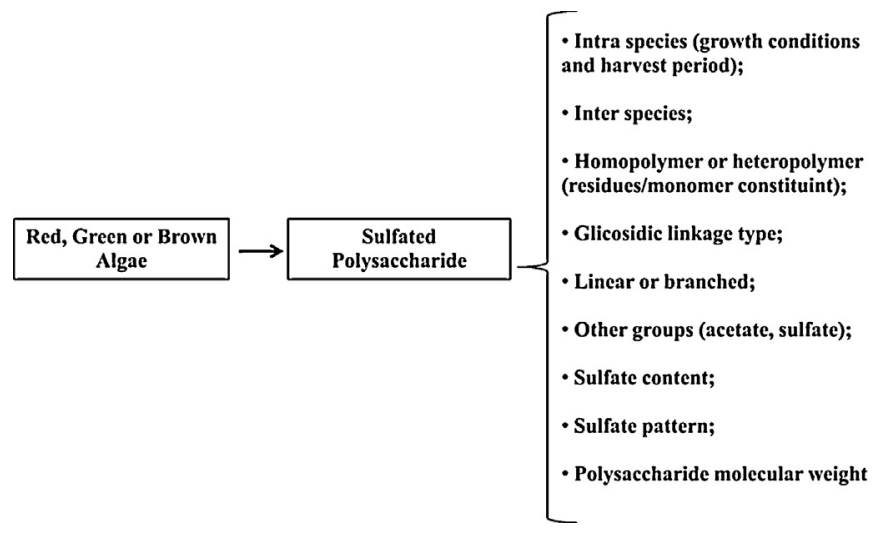

Fig. 1. Complexity in structure of sulfated polysaccharides from marine algae as a function of its various features.

presenting one of the possible monomers, L-fucose [11]. Table 1 shows some of the SPs reported in the literature by different researcher groups.

Studies with SPs from algae have been demonstrated that the structure varies from specie to specie and in the same plant, as well as its localization in plant tissue. The complexity in the structure of these compounds is due to a variety of linkages between the monosaccharides and the distribution of sulfate groups. Therefore, each polysaccharide may possess unique structural conformation and thus exhibits different biological activities [29,30] (Fig. 1).

\section{Biological activities of algal sulfated polysaccharides and structural requirements}

Algae's sulfated polysaccharide have attracted an increasing interest due to their physical properties, such as gelling, thickening and stabilizing ability as well as their beneficial biological activities [3]. Currently, the research on the chemical elucidation of algal products with pharmaceutical activity has increased, mainly in respect to binomial structure versus biological activity. Plenty of studies have focused in different biological activities of SPs as anti-inflammatory activity [31], antioxidant activity [32-34], antimicrobial activity [4], anticoagulant and antithrombotic activities [14,16], immunological activity [17], anticancer activity [18,23], even though still few of them have demonstrating the importance of a specific structural requirement in such activities.

\subsection{Anti-inflammatory activity}

The migration of proliferating leucocytes from blood to tissues is a characteristic of inflammatory process that causes various diseases (e.g. rheumathoid arthritis, sepsis). Wu et al. (2015) [31] investigated the anti-inflammatory activity of three algae species namely Porphyra tenera, Monostroma nitidum, and Sargassum cristaefolium (red, green and brown algae, respectively). The evaluation was based on inhibition of LPS-induced nitric oxide (NO) production in murine RAW264.7 macrophages. NO is an inflammatory mediator induced by inflammatory cytokines or bacterial LPS in cell types like macrophages. The researchers observed that $S$. cristaefolium had higher NO inhibitory activity. In accordance with several reports, in this study it was also evaluated the correlation between biological activity and molecular weight (fractions with 1193.2, 864.4 and $386.1 \mathrm{kDa}$ ) and polysaccharide sulfate content (original $31.1 \%$, desulfated polysaccharide with 0.84 and $9.42 \%$ and sulfurized with $50.83 \%$ ). Results showed that fractions with low molecular weight ( $386.1 \mathrm{kDa}$ ) and sulfate content (9.42\%) potently downregulated iNO expression [31].

\subsection{Antioxidant activity}

Some macroalgae live in complex habitats exposed to adverse conditions that lead to the formation of oxidizing agents suggesting that their cells possess mechanisms against oxidative stress. Besides polyphenolic compounds, SPs show potential antioxidant activity [34].

The in vitro methods used to evaluate antioxidant activity include measurement of reducing power, scavenging of radicals and reactive species, chelating properties and protection of lipid oxidation [34]. Zhang et al. [33] studied the antioxidant activity of polysaccharides extract from five algae: Laminaria japonica (brown alga), Porphyra haitanensis (red alga), Ulva pertusa, Enteromorpha linza and Bryopsis plumose (green algae). Firstly, they determined chemical composition and characterization of the samples LP (from L. japonica), PP (from P. haitanensis), UP (from U. pertusa), EP (from E. linza) and BP (from B. plumose)-polysaccharide extracts for each species. Total sugar (\%), sulfate content (\%) and molecular weight (kDa) for UP, LP, EP, BP and PP were, respectively: 33.4, 19.9 and 151 ; 66.7, 25.9 and 250; 47.9, 16.2 and 200; 41.8, 7.56 and 227; $78.9,17.7$ and 159. UP had in its composition, predominantly, the neutral sugar rhamnose and xylose; LP fucose and galactose; EP rhamnose and xylose; BP galactose and arabinose; PP galactose. All samples had stronger scavenging activity for superoxide radical than vitamin C, a well recognized natural antioxidant. For hydroxyl 
radical, the assays resulted in a concentration-dependent manner. UP, EP and PP showed good scavenging effect, although LP and BP had bad effect even at high polysaccharide concentrations. It was observed that sulfate group had high nucleophilic characteristic and could chelate with metal ion, leading to a stronger hydroxyl radical scavenging activities of the four samples when compared to BP. In respect to reducing power, UP, EP, BP and PP showed excellent effect, except of LP, which present the highest sulfate content. The reason was probably that the ability of donating a hydrogen atom declined because of the decreases of $\mathrm{OH}$ [33].

\subsection{Antimicrobial activity}

Most of the compounds responsible for the antimicrobial activity of seaweeds are phenolic and polysaccharide components, being the mechanism of action the stasis (microorganism's growth inhibition) or cidal (direct destruction of microorganism). The antimicrobial nature of algal polysaccharide is attributed to glycoprotein-receptors in bacteria cell-surface, for example, which is capable of recognizing and binding to charged polysaccharide molecules. However, antimicrobial activity of those types of polysaccharides is correlated to their molecular weight, charge density, sulfate content, structure and conformation [4].

Abou Zeid et al. [35] evaluated the water soluble polysaccharide extracts of both Pterocladia capillacea (red algae) and Dictyopteris membranacea (brown algae) and their antimicrobial activity. In the study, it was showed that the water temperature for extraction of algae polysaccharides was imperative not only to the polysaccharide yield but also for the presence of some sugars in those extracts. Total yield of the water-soluble polysaccharide extracted from $P$. capillace a and $D$. membranacea at $25^{\circ} \mathrm{C}$ (room temperature) was $2.87,2.14 \%$ and at $80^{\circ} \mathrm{C}$ was $6.46,3.89 \%$, respectively. P. capillacea polysaccharide hydrolyzate of cold water presented as major sugars galactose (25.36\%), glucose (20.59\%), arabinose (12.61\%) and fructose $(9.17 \%)$, while galactose $(17.81 \%)$, glucose $(16.99 \%)$, fructose $(9.38 \%)$ and mannose $(7.37 \%)$ were the major sugars of the hot hydrolyzate. $D$. membranacea cold water hydrolyzate was constituted by galacturonic acid (32.53\%), glucuronic acid (30.54\%) and fructose (7.56\%) as major sugars; while hot water hydrolyzate was galacturonic acid (27.32\%), glucuronic acid (22.02\%) and mannose $(6.01 \%)$. Cold and hot water extracts of $P$. capillacea showed wide range of antimicrobial activity against Gram positive (Bacillus cereus, Staphylococcus aureus, Streptococcus pyogen) and Gram negative (Pseudomonas flouresens) bacteria in addition to fungi (Fusarium oxysporium). Differently, D. membranacea extracts, of both cold and hot water, had no effect on Gram positive bacteria and fungi, despite of having good effect on Gram negative bacteria (Escherichia coli and P. flouresens). Based on other reports and attained results, authors concluded that the chemical and structural characteristics of the marine algal polysaccharides are considered a prerequisite for understanding their biological activity [35].

\subsection{Anticoagulant and antithrombotic activities}

One disorder of blood coagulation leads to an increased risk of clotting (thrombosis), making the use of anticoagulants, substances that prevent coagulation, necessary. An example of widely used medication for thrombotic disorders is the heparin. Heparin is a highly sulfated polysaccharide present in mammalian tissues (not in algae). Nevertheless, there is a high demand to obtain novel structures with anticoagulant and antithrombotic activities due to the bad and long-term side effects of heparin, as the risk of excessive bleeding and induction of thrombocytopenia [10].

Grauffel et al. [16] screened the anticoagulant properties of various fucan fractions extracted from different algal species (brown algae) to assess the relationship between fucan structure and activ- ity. Fucans were extracted from Laminaria digitata (Ld), Pelvetia canaliculata (Pc), Fucus vesiculosus (Fv), Sargassum muticum (Sm) and Ascophyllum nodosum (An) with different solvents: cold water, Triton, hot-acidic water, hot-alkaline water. The authors observed that coagulation assays (thrombin clotting time and anticoagulant activity) were very dependent on fucans chemical compositions. One of the results that corroborate with this conclusion occurred in extracts obtained with Triton-fucans of Pc and Fv had higher contents of fucose and sulfate and lower levels of uronic acid and galactose and consistently exhibited higher anticoagulant activities compared with those extracted from Ld or Sm. A remark of the study was that fucans with high sulfate content presented a significantly increased anticoagulant activity [16].

\subsection{Immunological activity}

It is well known that marine algae are great sources of polysaccharides. Carrageenans isolated from some red algae, particularly, have been used to induce various effects on immune system. As carrageenans interact with a variety of sulfated polysaccharidesbinding proteins, the immune response could be inhibited or stimulated. Immune-suppression action, for example, is due to transduction block of inflammatory signal induced by proinflammatory cytokines, suppression of complement activation and inhibition of two other processes: leukocyte-adhesion and leukocyte-passing through the endothelium. Although the initiation of an immune response can be achieved through interaction between immune cells and SPs, the structure of this polymer may play a critical role in their controversial effects [17].

Bondu et al. [17] investigated the structural features of carrageenan extracted from the red alga Solieria chordalis and the influence of polymer molecular weight over immunological activity. The structure was determined by CG-MS, NMR and FTIR spectroscopies, elucidating a galactan polymer with pyruvate acetal- and methyl ether-substitutions in carrabiose repeating units in the carrageenan. The protection against disease exerted by immune system within the organism is mediated by immune cells (macrophage, lymphocytes, natural killers-NK) and molecules (complement and antibody). The activities of these cells and molecules rely on mechanisms that constitute the innate immunity (e.g. phagocytosis, ADCC-antibody-dependent natural killer cells activity, direct NK citotoxicity). In this study, the highest immunological activities, mainly in the direct cytoxicity by NK cells and on the ADCC mechanism, were attained with low molecular weight fractions of the carrageenan (after chemical treatment: free-radical depolymerization and mild-acid hydrolysis). Authors concluded that the low molecular fractions demonstrated good immunostimulating properties due to enhancement of neutrophil phagocytosis, cytotoxicity by natural killer cells, antibody-dependent cell cytotoxicity and stimulation of lymphocyte proliferation (immunological assays) [17].

\subsection{Anticancer activity}

Several studies have reported that SPs inhibit tumor cell proliferation and tumor cell adhesion. Indeed, the exact action mechanisms are not yet understood [9].

A study dealing with the impact of sulfated polysaccharide molecular weight showed that only the native fucoidan from the brown alga Fucus evanescens exerted anticancer activities in human malignant melanoma cell lines: SK-MEL-28 and SK-MEL-5. Native polymer was subjected to autohydrolysis for depolymerization and MALDI-TOFMS analysis (for both native and fragmented polysaccharide). Native fucoidan exhibited a $60 \mathrm{kDa}$ weight and highly sulfated pattern (28\%). Researchers observed that fragments with low molecular weight had no action into cell proliferation in 
both cell lines and colony formation on SK-MEL-5. On the other hand, these fragments presented almost the same inhibition activity against colony formation for SK-MEL28, in comparison to the native fucoidan. Probably, the inhibition activity for SK-MEL-28 cell lines is dependent of sulfate groups and $(1 \rightarrow 4)$-linked $\alpha$-L-fucose residues in the main chain of fucoidan (native)/oligosaccharides (fragments). The results are in accordance with other reports; this means that a reduction of molecular weight of fucoidans and an oversulfation potentiated anticancer activity [18].

\section{Structural modifications of sulfated polysaccharide}

Modified SPs are those not only extract from their natural sources, but those that was subjected to consciously modification by the use of physical, chemical or enzymatic treatments. The major reasons for modification of SPs aim both structural evaluation and the enhancement of their biological activity, simplifying structural and structure/function studies. Relatively few studies have interpreted the biological activity of SPs in terms of molecular structure diversity. As previously mentioned, the diversity concerns first the variety of monosaccharides present in the molecules, that accounts to carbon 1 anomery ( $\alpha$ or $\beta$ ) and the absolute configuration of the sugars ( $\mathrm{D}$ or $\mathrm{L}$ ). In addition, the glycosidic linkage between monosaccharides and their substitution (nature, yield, and position of substituents) must be elucidated. Another important feature that should be considered is the molecule size characterized by polymerization degree [7]. The modification of natively bioactive polysaccharides could not only extend their applications, but also introduce bioactivity (functionalization) in SPs that do not possess them or improving the innate bioactivities (Fig. 2).

Some environment friendly processes for extraction of polysaccharides have been successfully used, prior structural elucidation and modification. These processes could be designated as pretreatments, such as supercritical fluid extraction, microwave-assisted extraction and hot-water extraction. Effectiveness is based on higher extraction efficacy, low cost and structure preservation ability. Enzymatic pretreatments are also employed since they reduce extraction time, diminish energy consumption, minimizes the usage of solvents, increase the yield, and mainly preserve biological activities [3]. Generally, polysaccharides are submitted to NMR spectroscopy after pretreatments aiming structural analysis [14,21] (Fig. 2).

As an example, it has been reported that SPs derived from marine algae are alternative sources for manufacture of novel anticoagulant drugs. The activities of those types of sulfated polysaccharides are compared to a well known standard, the heparins. Heparins are SPs currently used as anticoagulant drugs for more than 50 years, being extracted from mammalian tissues. In the same manner, the activity and its potency will depend on a specific pentasaccharide sequence with high affinity for the serine protease inhibitor antithrombin, this means a specific structure $[14,5]$.

Recent insights into the structures elucidation may explain their influence and importance over biological activities of SPs, which could be attained after polymer modification [23-25].

\subsection{Physical modification}

Physical methods for modification of SPs are considered environmentally safe and can be separated into: ultrasonic, microwave and thermal depolymeraziation, among others.

Holme et al. [36] investigated the thermal depolymerization of two commercial purified alginates, one with high content of glucuronic acids and another with mannuronic acid. Thermal treatment was attained at moderate temperatures $60-120^{\circ} \mathrm{C}$ in order to evaluate its kinetic, using intrinsic viscosity data for analysis. Activation energies for the depolymerization of the alginates were determined to get information about possible depolymerization mechanisms. The authors demonstrated that oxidative-reductive depolymerization mechanism was not responsible for the thermal depolymerization, even in the presence of oxygen, and that mannuronic acid-rich alginate is more susceptible to acid hydrolysis than the glucuronic acid-rich alginate, when $\mathrm{pH}$ solutions varied from 3.8 to 9.5 (influence of $\mathrm{H}^{+}$and $\mathrm{OH}^{-}$) [36].

Zhou et al. [37] evaluated the in vivo antitumor and immunomodulation activities of different molecular weight $\lambda$ carrageenan from Chondrus ocellatus (red alga). To attain different fractions of sulfated polysaccharide, purified $\lambda$-carrageenan was submitted to microwave short reaction times $(0-10 \mathrm{~min})$ and stress (0-15 atm). The fractions were distinct in molecular weight, although contents of total sugar and sulfate group of most samples were similar to each other. Molecular weight of $\lambda$-carrageenan could influence on its antitumor and immunological activities: highest inhibition rate of cell tumors and lymphocyte proliferation ratio were observed with shorter fractions (9.3 and $15 \mathrm{kDa}$ ) [37].

In another study, changes in intrinsic viscosity during ultrasonic depolymerization of agarose, $\mathrm{k}$ - and $\mathrm{\iota}$-carrageenans in water were investigated. Authors observed that the intrinsic viscosity agarose and carrageenans ultrasonicated at $0.5 \mathrm{wt} \%$ decreased exponentially with increasing ultrasonic time. It was suggested the existence of a linear relationship between depolymerization ratio and intrinsic viscosity by low-frequency, highintensity ultrasound $\left(35 \mathrm{kHz}, 300 \mathrm{~W} / \mathrm{cm}^{2}\right)$ in the order of agarose $>$ k-carrageenan $>\mathrm{\iota}$ carrageenans [38].

Reduction of polymer size is the main effect over SPs by using physical treatments. However, when these processes are associated with high temperature $\left(>100^{\circ} \mathrm{C}\right)$ and the presence of residual amounts of proteins or peptides in the sample, Maillard reaction could occur, thereby, forming unwanted molecules (toxic). In addition, depolymerization induced by free radical mechanisms may produce combinations between radicals from carbohydrate derivatives, generating undesirable molecules [7].

\subsection{Chemical modification}

There is an increasing interest in polysaccharide depolymerization reactions due to three roles: applications in important industrial process (e.g. brewing), in chemical structural elucidation and bioactivities studies [39,7]. More common methods employed are acid hydrolysis with $\mathrm{HCl}$ or $\mathrm{H}_{2} \mathrm{SO}_{4}$ (used mostly for analytical purposes), alkaline hydrolysis (with aqueous $0.5 \mathrm{M} \mathrm{NaOH}$ ), and oxidation using $\mathrm{Fe}-\mathrm{H}_{2} \mathrm{O}_{2}$.

Controlled acid hydrolysis is used to obtain SPs with changes on the length, producing oligomers of varied molecular weight. At lower $\mathrm{pH}$ values, linkages between uronic acid residues are very stable. However, linkages between neutral sugars could be susceptible to acid action, resulting in a fast degradation of side-chains to oligomers and monomers. The backbone is more resistant to glycosidic bonds cleavage [40]. Oligo-ulvans could be obtained by depolymerization of ulvans (a sulfated polysaccharides present in green seaweeds) from Ulva armoricana, U. rigida, U. lactuca, U. compressa and $U$. intestinalis using $2 \mathrm{M} \mathrm{HCl}$ at $100^{\circ} \mathrm{C}$ for $45 \mathrm{~min}$, which produced mainly monosaccharide and disaccharide units. Oligoalginates (from brown seaweeds), formed by D-glucuronic acid or D-mannuronic acid with an average molecular weight of $3.5 \mathrm{kDa}$, were obtained by acid hydrolysis of alginates extracted from Lessonia trabeculata and $L$. vadosa [41]. Although this method is rather employed, it is not the best choice, since cleavages of glycosidic linkages are not specific and a wide diversity of oligomers can be obtained [7]. 

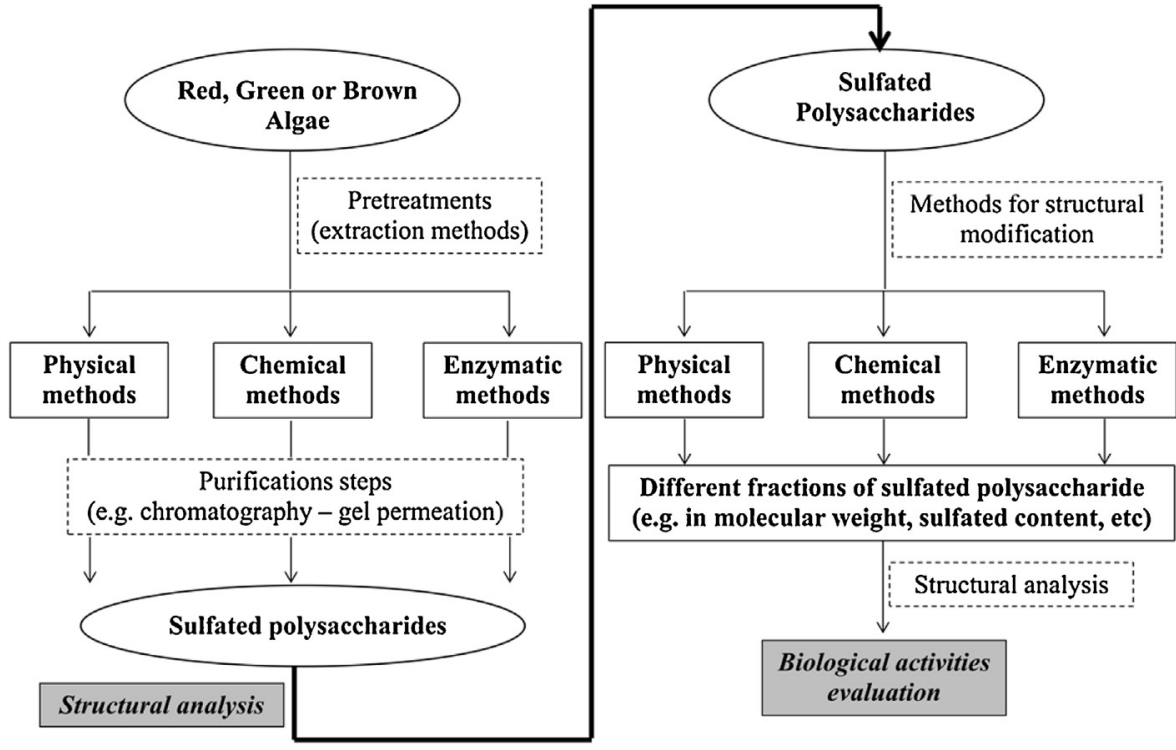

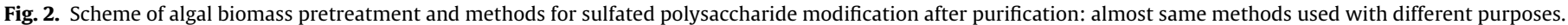

The depolymerization of polysaccharides over free radical induced oxidation could be another method of choice. In the case of Fenton-like reaction, transition metals as copper or iron in the presence of $\mathrm{H}_{2} \mathrm{O}_{2}$ generate hydroxyl free radicals. In some cases, the radical attack glycosidic linkage and in others the polysaccharide pyranosidic ring is attacked $[7,39]$. In a literature report, the oxidation of laminaran molecules by $\mathrm{H}_{2} \mathrm{O}_{2} / \mathrm{FeSO}_{4}$ redox system generated aldehyde groups. Some laminaran molecules were cleaved into small oligosaccharide fragments, although the reaction also promoted cleavage of glucose rings [42].

The main disadvantages of using chemical methods are the extreme conditions for the reaction occurrence: usage of strong acids or bases and elevated temperatures. Those conditions may lead to polysaccharide degradation.

\subsection{Enzymatic modification}

The production of large amounts of oligomers from SPs could be attained using enzymes from different species of microorganisms (filamentous fungi, yeasts and bacteria). In addition, numerous enzymes are needed to polymers modification due to their structural diversity. Specific enzymes could be used to provide tailored oligosaccharides for biological studies. In the same way, enzymatic methods could be employed to simplify samples aiming the deduction of original sulfated polysaccharide structure [5]. However, information about wild or recombinant microorganisms able to produce those types of enzymes is scarce.

In despite of the enzymes application in sulfated polysaccharide derivatization, widely used in structural analysis, the search for microorganisms and culture optimization and purification of those enzymes for the studies of polysaccharides biological activities are recent in comparison to the extensive usage of other treatments [8]. The use of microorganisms to produce enzymes that could be applied to SPs modifications present some advantages such as: rapid growth in culture medium constituted by different substrates; production of the enzymes in feasible quantities and conditions; easy manipulation and, if well preserved, microorganisms could be reactivated and reused.

\subsubsection{Hydrolases and lyases}

Polysaccharides structural modification could be achieved using either lyases or hydrolases. For example, specific lyases activities a)

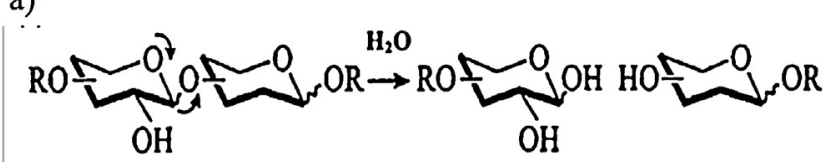

b)

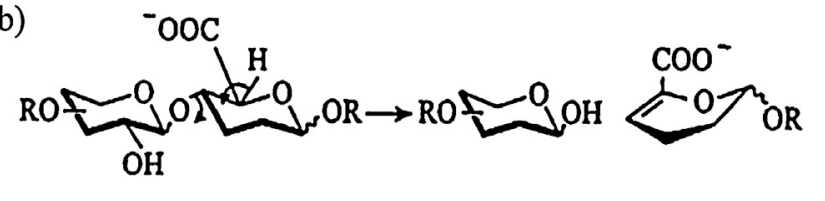

Fig. 3. Scheme of polysaccharide cleavage enzymatic mechanism: (a) a polysaccharide hydrolase; (b) a polysaccharide lyase (Courtois) [7]

are mainly observed on neutral (e.g. $\alpha-1,4$-glucan) or anionic (e.g. alginate) polymers leading to the production of oligosaccharides with degree of polymerization ranging from 2 to 5 [43].

The expression of Pseudoalteromonas elyakovii alginate lyase in E. coli using culture medium with calcium compounds (as inducers) was evaluated by Sawabe et al. [44]. The alginate lyase produced by $P$. elyakovii IAM 14596 degrades block structures from sodium alginate and generates tri- to octa-oligouronates. Although the expression of active enzyme in cultivated $E$. coli could be difficult to attain, the medium supplementation with glyceric acid calcium and calcium propionate influenced active expression enhancement. This finding over expression of the active recombinant enzyme could thus be an important contribution to marine biotechnology [44]. Polysaccharides lyases cleavage mechanism consists of a $\beta$ elimination that results into the formation of a double bond in the newly generated nonreducing end [7] (Fig. 3).

Enzymes that catalyze fucoidan or fucan degradation are nominated fucoidan hydrolases. According to Berteau and Mulloy [5] there are, at least, two types of glycosidases that presents fucans as substrate, fucan sulfate hydrolase or fucoidanase (EC 3.2.1.44) and fucosidase (EC 3.2.1.51, EC 3.2.1.63, EC 3.2.1.111 or EC 3.2.1.127). Endo-fucoidanase cleaves glycosic bonds of the polysaccharides, leading to molecular weight reduction. On the other hand, exo-fucoidanase is active over polysaccharides ends, releasing oligosaccharides with slight decrease of the molecular weight. Fucosidases activities release L-fucose from the non-reducing end of polysaccharide. Bacterial fucoidanases have been subject of stud- 
ies, and at least one strain of bacteria was patented due to the production of fucoidan oligosaccharides without purification of the enzyme fucoidanase [5]. Rodríguez-Jasso et al. [45] studied the production of fucoidanases in solid state fermentation, with medium conditions optimization and scale-up. They observed the influence of fungal strains (Aspergillus niger PSH and Mucor sp. 3P), algal substrates (untreated, autohydrolyzed, and microwave processed seaweed $F$. vesiculosus) and fermentation with or without agitation, on the enzyme production. The best conditions consisted in using the fungus Mucor sp. strain 3P, autohydrolyzed alga as substrate and fermentation system with agitation (fucoidanase activity of $3.82 \mathrm{U} \mathrm{L}^{-1}$ ) [45]. Fucoidanases can hydrolyze fucoidan to sulfate low molecular weight fractions without removal of its side substitute groups [46].

Accordingly to Descamps et al. (2006) [47], in spite of polysaccharides from brown algae (fucans) being considered biologically active compounds, sources with fucanase activity are scarce. Study developed by those authors reported the isolation, characterization, and culture conditions of a bacterium, member of the family Flavobacteriaceae, during production of fucoidan endo-hydrolase. The extracellular enzyme was capable to degrade $P$. canaliculata fucoidan, releasing tetrasaccharide, made of the repetition of two units of $\alpha-1 \rightarrow 3$-L-fucopyranose-2-sulfate and $\alpha-1 \rightarrow 4$ L-fucopyranose-2,3-disulfate, with the 3 -linked residues at the nonreducing end, and a hexasaccharide in the same homologous series. This enzyme was a useful tool for the preparation of biologically active low molecular weight fucans [47]. In another study, Colin et al. (2006) [48] characterized a novel glycoside hydrolase. The gene $f c n A$ from a Flavobacteriaceae was cloned and sequenced and the enzyme produced in E. coli [48].

Kysaykin et al. (2006) studied the fucoidanases activities and specificities of two different enzyme sources: from the marine mollusk Littoria kurila and from a marine bacterium, Pseudoalteromonas citrea. They concluded that, even though fucoidanases had been found only in marine organisms with extremely low activities, the starting level of fucoidanase activity in the microbial source was one order of magnitude higher than in hepatopancreas of L. kurila. In addition, the study showed that the fucoidanases from both $L$. kurila and $P$. citrea KMM 3296 had similar specificity, cleaving, predominantly, $\alpha-(1 \rightarrow 3)$-glycosidic bonds between fucose residues. On the other hand, the released products were different, with bacterial fucoidanase forming mainly di-, tri-, tetra-, and pentafucooligosaccharides, whereas the basic form of fucoidanase from the mollusk yielded higher molecular weight products from fucoidan (of 3-10 kDa) [8].

Algal polysaccharides constitute a carbon source for several marine microorganisms, which degrade this polymer by secreting specific hydrolases. In this sense, Ziayoddin et al. (2010) [2] evaluated the isolation of a Gram negative bacteria, Pseudomonas aeruginosa ZSL-2, from marine sample. The researchers observed that the selected strain was able to degrade agar and carrageenans due to the production of extracellular agarase and carrageenase. The agarase hydrolyse products (agar-olygosaccharides) are usually employed as functional food ingredients. $\kappa$-carrageenase hydrolyzes $\beta-1,4$ linkages of $\kappa$-carrageenan and release olygosaccharides. This enzyme is a useful tool for structural analysis of SPs [2]. Structural analysis is usually done by nuclear magnetic resonance (NMR) spectroscopy, but specific enzymatic degradation followed by isolation and identification of higher oligosaccharide fragments is required for elucidation of the real sequence of different structural elements in complex polysaccharide molecules [6]. Yao et al. (2013) [49] also studied production and biochemical characterization of a $\kappa$-carrageenase of marine Cellulophaga lytica strain N5-2, isolated from the sediment of carrageenan production base. Purified enzyme presented $40.8 \mathrm{kDa}$ of molecular weight; high activity of $1170 \mathrm{U} / \mathrm{mg}$ protein; $\mathrm{K}_{\mathrm{m}}$ value of a)

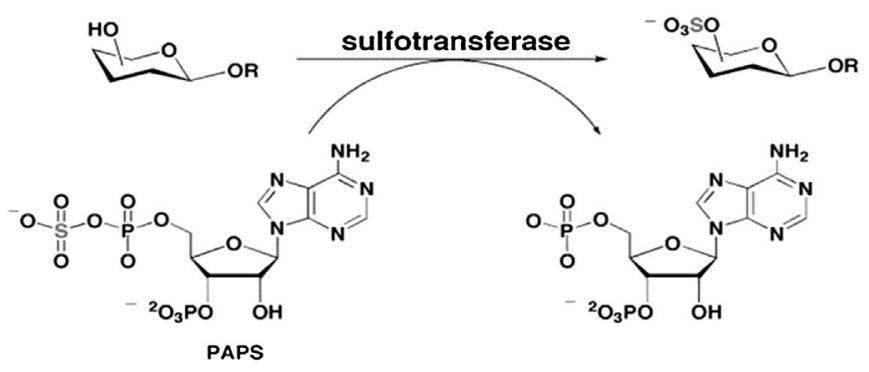

b)

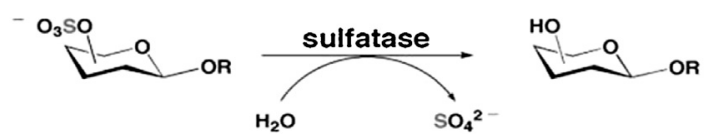

Fig. 4. Reactions catalyzed by (a) sulfotransferase (e.g. transfer of sulfuryl group from an activated donor, 3'-phosphoadenosine-5'-phosphosulfate-PAPS) and (b) sufatases (Mougous et al.) [51].

$1.647 \mathrm{mg} / \mathrm{mL}$ and a $\mathrm{V}_{\max }$ value of $8.7 \mu \mathrm{mol} / \mathrm{min} / \mathrm{mg}$ when the reaction was carried out at $35^{\circ} \mathrm{C}$ and $\mathrm{pH} 7.0$, using $\mathrm{\kappa}$-carrageenan as substrate. The enzyme showed specific activity over $\beta$-1,4 linkage of k-carrageenan, releasing the products $\kappa$-neocarrabiose-sulfate, $\kappa$-neocarrahexaose-sulfate and $\kappa$-neocarraoctaose-sulfate [49].

In the case of polysaccharide hydrolases, cleavage mechanism leads to an overall retention or to an inversion of anomeric configuration, this means an oligomer preparation with a mixture of molecules (reducing end with $\alpha$ or $\beta$ configuration) [7] (Fig. 3).

\subsubsection{Sulfotransferases and sulfatases}

Besides glycoside linkage types, the determination of attached sulfate esters along SPs backbone is also required during their structure analysis. Linkages between monsaccharides are determined by methylation and the positions of the sulfate groups can be elucidated through comparison of methylated native polysaccharides to that of their desulfated counterparts. In this sense, desulfation of the polysaccharide without cleavage of its chain linkages becomes necessary for an accurate structural determination. The use of sulfatases represents a more specific approach to desulfation although enzymatic method are not the frequent method of choice, probably due to the lack of commercially available enzymes [50].

Thereby, another two enzyme classes are also important in sulfated polysaccharide modification: the sulfotransferases and the sulfatases. The former is responsible for the introduction and the subsequent for the removal of sulfate esters.

Sulfotransferases catalyze the transfer of a sulfuryl group to a small molecule, a carbohydrate, or a tyrosine residue within a protein. Sulfatases are able to catalyze the hydrolysis of sulfate esters (or $N$-sulfates) to an alcohol (or amine) and free sulfate [51] (Fig. 4).

In contrast to the large number of sulfotransferases that have been characterized in mammals, there have been few such enzymes studied in microorganisms (e.g. bacteria) [51].

Different enzymes produced by various microorganisms species have been studied. Although the applications of these enzymes were not directed to sulfated polysaccharide modifications, it could be a source of investigation. For example, the production of galactosidases by A. niger [52] or Debaryomyces hansenii UFV-1 [53] (Table 2).

Studies with enzymes that are able to modify sulfated polyssacharides have been demonstrating importance, mainly in respect to the discovery of novel enzymes and microorganisms sources, in addition to the elucidation of the role of the enzymes in polysaccharides degradation/modification. 
Table 2

Enzymes used in polysaccharides modification.

\begin{tabular}{|c|c|c|c|}
\hline Enzyme & Activity & Microorganisms & Reference \\
\hline Arylsulfatase or aryl-sulfohyrolase & $\begin{array}{l}\text { Produced during S starvation } \\
\text { (substrate = sulfate esters) }\end{array}$ & $\begin{array}{l}\text { Microbacterium sp. Rhodococcus } \\
\text { sp. Streptomyces sp. }\end{array}$ & (Cregut et al.) [54] \\
\hline $\begin{array}{l}\text { Galactosidases ( } \alpha \text {-D-galactoside galactohydrolase } \\
\text { and } \beta \text {-D-galactoside galactohydrolase) }\end{array}$ & $\begin{array}{l}\text { Hydrolisis of terminally linked galactosidic } \\
\text { residues (substrates = simple } \\
\text { galactose-containing olygosaccharides or } \\
\text { complex polysaccharides) }\end{array}$ & Aspergillus niger & (Manzanares et al.) [52] \\
\hline$\alpha$-D-galactoside galactohydrolase & $\begin{array}{l}\text { Hydrolysis of terminal } \alpha-1,6 \text { linked } \\
\text { D-galactose residues present in galacto } \\
\text { oligosaccharides of } \\
\text { sugars of the raffinose family and } \\
\text { galactomannan polysaccharides }\end{array}$ & $\begin{array}{l}\text { Debaryomyces } \\
\text { hansenii UFV-1 }\end{array}$ & (Viana et al.) [53] \\
\hline $\begin{array}{l}\text { Different hydrolytic enzymes } \\
\text { (N-acetyl- } \beta \text {-D-glucosaminidase; } \alpha \text {-galactosidase; } \\
\beta \text {-D-xylopyranosidase; Acid sulphatase) }\end{array}$ & $\begin{array}{l}\text { Cleavage of polysaccharides present in cereal } \\
\text { grains (wheat and barley) }\end{array}$ & $\begin{array}{l}11 \text { species of Aspergillus, } \\
\text { Eurotium and Penicillium }\end{array}$ & (Jain et al.) [55] \\
\hline Glucoamylase ( $\alpha$-1,4-glucan-glucohydrolases) & $\begin{array}{l}\text { Hydrolyzes } \\
1,4-\alpha \text {-glycosidic bonds from the non-reducing } \\
\text { ends of starch and 1,6- } \alpha \text {-glucosidic linkages in } \\
\text { polysaccharides yielding glucose as the } \\
\text { end-product }\end{array}$ & Aspergillus sp. JAN-25 & (El-Gendy) [56] \\
\hline Cellulases and xylanases & $\begin{array}{l}\text { Hydrolysis of vegetal biomass polysaccharides: } \\
\text { cellulose and hemicellulose }\end{array}$ & Penicillium echinulatum & (Camassola and Dillon) [57] \\
\hline $\begin{array}{l}\text { Cellulase ( } \beta \text {-1,4-endoglucanase; } \\
\beta \text {-1,4-exoglucanase; cellobiase of cellulase } \\
\text { system) }\end{array}$ & $\begin{array}{l}\text { Hydrolysis of corncob natural cellulose to } \\
\text { glucose }\end{array}$ & $\begin{array}{l}\text { Trichoderma reesei } \mathrm{ZU}-02 \text { and } \\
\text { Aspergillus niger } \mathrm{ZU}-07\end{array}$ & (Chen et al.) [58] \\
\hline
\end{tabular}
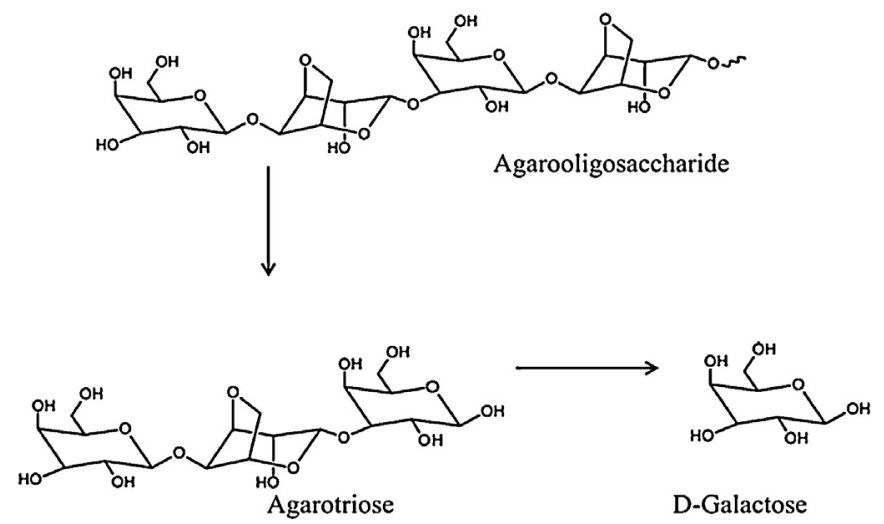

Fig. 5. Reaction catalyzed by a novel $\beta$-galactosidase in the agarose derivedoligosaccharide, agarotriose the smallest odd-numbered oligosaccharide, and release of galactose unit (adapted from Lee et al.) [59].

Lee et al. (2014) discovered a novel $\beta$-galactosidase in Vibrio sp. strain EJY3, a marine bacterium. The enzyme offers the advantage of hydrolyzing agarooligosaccharides (such as agarotriose present in red macroalgae agarose or agar) into galactose from the nonreducing end of the oligosaccharide, that supplement the missing function of the currently available $\beta$-agarase system. The authors focused on the use of the enzyme in the production of fermentable sugar from algae biomass (Fig. 5) [59].

Miyanaga et al. [60] studied family 54 of $\alpha$-Larabinofuranosidase, an enzyme that catalyses the hydrolysis of the $\alpha-1,2-, \alpha-1,3-$, and $\alpha-1,5$-L-arabinofuranosidic bonds in $\mathrm{L}-$ arabinose containing hemicelluloses such as arabinoxylan present in plants. The authors observed that this glycoside hydrolase from Aspergillus kawachii has two domains, a catalytic and an arabinose-biding domain, the latter being the first example of a carbohydrate-biding module able to recognize monosaccharides of branched hemicelluloses.

Hogg et al. [61] evaluated the differences in the molecular architecture and biochemical properties of two glycosides hydrolases families (GHs) of Cellvibrio japonicas mannanases, GH5 and GH26. They proposed that GH5 mannanases are able to bind crystalline polysaccharide present in integral plant cell wall, while GH26 man- nanases act over polysaccharides and oligosaccharides, such as galacto-mannan and manno-olygosaccharides, respectively.

When considering the modification of SPs, enzymatic methods should be preferred since they are safe and green and the approaches are selective and non-toxic (chemical solvents are not required) [3].

\section{Conclusions and future trends}

SPs from marine algae have long been studied, mainly due to their particular bioactive properties. Characteristics like biocompatibility, biodegradability, as well as some specific therapeutic activities made those polymers studies of great importance.

From literature, it can be inferred that, even though the researches have been demonstrating in vitro activities of various SPs, there are still few studies focusing on structural analysis and its influence on biological activities.

Natively biological activities, isolation, characterization and the structural modification of SPs to create novel opportunities for important features are glycobiology areas that should be encouraged. Further knowledge of polysaccharides enzymatic treatments are also necessary, which could be used in terms of polymer structure modifications. However, exploitation of microbial enzymes, screening and identification of microorganisms with this purpose would provide a better understanding of their use for sulfated polysaccharide biological activities improvement.

\section{Acknowledgements}

This review was prepared in the framework of two projects, one financed by CNPq (number 552620/2011-4) and the other by FAPESP (2013/19486-0).

\section{References}

[1] M.Z.I. Mollah, M.A. Khan, R.A. Khan, Effect of gamma irradiated sodium alginate on red amaranth (Amaranthuscruentus L.) as growth promoter, Radiat. Phys. Chem. 78 (2009) 61-64.

[2] M. Ziayoddin, S. Manohar, J. Lalitha, Isolation of agar degrading bacterium Pseudomonas aeruginosa ZSL-2 from a marine sample, Bioscan Int. Q. J. Life Sci. 5 (2) (2010) 279-283. 
[3] J. Liu, S. Willför, C. Xu, A review of bioactive plant polysaccharides: biological activities, functionalization, and biomedical applications, Bioact. Carbohydr. Diet. Fibre 5 (2015) 31-61.

[4] N. Abu-Ghannam, G. Rajauria, Antimicrobial activity of compounds isolated from algae, chapter 8, in: H. Dominguez (Ed.), Functional Ingredients from Algae for Foods and Nutracceuticals, Woodhead Publishing, 2013.

[5] O. Berteau, B. Mulloy, Sulfated fucans, fresh perspectives: structures, functions, and biological properties of sulfated fucans and an overview of enzymes active toward this class of polysaccharide, Glycobiology 13 (6) (2003) 29-40.

[6] A. Usov, N.D. Zelinsky, Chemical structures of algal polysaccharides, chapter 2, in: H. Dominguez (Ed.), Functional Ingredients from Algae for Foods and Nutraceuticals, Woodhead Publishing, 2013.

[7] J. Courtois, Oligosaccharides from land plants and algae: production and applications in therapeutics and biotechnology, Curr. Opin. Microbiol. 12 (2009) 261-273.

[8] M.I. Kusaykin, A.O. Chizhov, A.A. Grachev, S.A. Alekseeva, I. Yu Bakunina, O.I. Nedashkovskaya, V.V. Sova, T.N. Zvyagintseva, A comparative study of specificity of fucoidanases from marine microorganisms and invertebrates, J. Appl. Phycol. 18 (2006) 369-373.

[9] I. Wijesekara, R. Pangestuti, S.-K. Kim, Biological activities and potential health benefits of sulfated polysaccharides derived from marine algae, Carbohydr. Polym. 84 (2011) 14-21.

[10] W.A.J.P. Wijesinghe, Y.-J. Jeon, Biological activities and potential industrial applications of fucose rich sulfated polysaccharides and fucoidans isolated from brown seaweeds: a review, Carbohydr. Polym. 88 (2012) 13-20.

[11] D. Rodrigues, A.C. Freitas, L. Pereira, T.A.P. Rocha-Santos, M.W. Vasconcelos, M. Roriz, L.M. Rodríguez-Alcalá, A.M.P. Gomes, A.C. Duarte, Chemical composition of red, brown and green macroalgae from Buarcos bay in Central West Coast of Portugal, Food Chem. 183 (2015) 197-207.

[12] K.E. Arfors, K. Ley, Sulfated polysaccharides in inflammation, J. Lab. Clin. Med. 121 (1993) 201-202.

[13] C.P. Dietrich, G.G.M. Farias, L.R.D. Abreu, L.F. Silva, E.L. Leite, H.B. Nader, A new approach for characterization of polysaccharides from algae: presence of four main acidic polysaccharides in three species of the class Phaeophyceae, Plant Sci. 108 (1995) 143-153.

[14] M.G. Pereira, N.M.B. Benevides, M.R.S. Melo, A.P. Valente, F.R. Melo, P.A.S. Mourão, Structure and anticoagulant activity of a sulfated galactan from the red alga, Gelidium crinale. Is there a specific structural requirement for the anticoagulant action? Carbohydr. Res. 340 (2005) 2015-2023.

[15] B. Larsen, D.M.S.A. Salem, M.A.E. Sallam, M.M. Mishrikey, A.I. Beltagy, Characterization of the alginates from algae harvested at the Egyptian Red Sea coast, Carbohydr. Res. 338 (2003) 2325-2336.

[16] V. Grauffel, B. Kloareg, S. Mabeau, P. Durand, J. Jozefonvicz, New natural polysaccharides with potent antithrombic activity: fucans from brown algae, Biomaterials 10 (1989) 363-368.

[17] S. Bondu, E. Deslandes, M.S. Fabre, C. Berthou, Y. Guangli, Carrageenan from Solieria chordalis (Gigartinales): structural analysis and immunological activities of the low molecular weight fractions, Carbohydr. Polym. 81 (2010) 448-460.

[18] S.D. Anastyuk, N.M. Shevchenko, S.P. Ermakova, O.S. Vishchuk, E.L. Nazarenko, P.S. Dmitrenok, T.N. Zvyagintseva, Anticancer activity in vitro of a fucoidan from the brown alga Fucus evanescens and its low-molecular fragments, structurally characterized by tandem mass-spectrometry, Carbohydr. Polym. 87 (2012) 186-194.

[19] M. Arman, S.A.U. Qader, Structural analysis of kappa-carrageenan isolated from Hypnea musciformis (red algae) and evaluation as an elicitor of plant defense mechanism, Carbohydr. Polym. 88 (2012) 1264-1271.

[20] P. Wang, X. Zhao, Y. Lv, M. Li, X. Liu, G. Li, G. Yu, Structural and compositional characteristics of hybrid carrageenans from red algae Chondracanthus chamissoi, Carbohydr. Polym. 89 (2012) 914-919.

[21] Y. Hu, G. Yu, X. Zhao, Y. Wang, X. Sun, G. Jiao, X. Zhao, W. Chaia, Structural characterization of natural ideal 6-O-sulfated agarose from red alga Gloiopeltis furcata, Carbohydr. Polym. 89 (2012) 883-889.

[22] C.M.P.G. Dore, M.G.C.F. Alves, L.S.E.P. Will, T.G. Costa, D.A. Sabry, L.A.R.S. Rêgo, C.M. Accardo, H.A.O. Rocha, L.G.A. Filgueira, E.L. Leite, A sulfated polysaccharide, fucans, isolated from brown algae Sargassum vulgare with anticoagulant, antithrombotic, antioxidant and anti-inflammatory effects, Carbohydr. Polym. 91 (2013) 467-475.

[23] R.V. Menshova, S.P. Ermakova, S.D. Anastyuk, V.V. Isakov, Y.V. Dubrovskaya, M.I. Kusaykin, B.-H. Um, T.N. Zvyagintseva, Structure, enzymatic transformation and anticancer activity of branched high molecular weight laminaran from brown alga Eisenia bicyclis, Carbohydr. Polym. 99 (2014) 101-109.

[24] N.M. Shevchenko, S.D. Anastyuk, R.V. Menshova, O.S. Vishchuk, V.I. Isakov, P.A. Zadorozhny, T.V. Sikorskaya, T.N. Zvyagintseva, Further studies on structure of fucoidan from brown alga Saccharina gurjanovae, Carbohydr. Polym. 121 (2014) 207-216.

[25] Q. Cong, F. Xiao, W. Liao, Q. Dong, K. Ding, Structure and biological activities of an alginate from Sargassum fusiforme, and its sulfated derivative, Int. J. Biol Macromol. 69 (2014) 252-259.

[26] T.N. Zvyagintseva, N.M. Shevchenko, E.L. Nazarenko, V.I. Gorbach, A.M. Urvantseva, M.I. Kiseleva, V.V. Isakov, Water-soluble polysaccharides of some brown algae of the Russian Far-East. Structure and biological action of low-molecular mass polyuronans, J. Exp. Mar. Biol. Ecol. 320 (2005) 123-131.
[27] A. Ghannam, A. Abbas, H. Alek, Z. Al-Waari, M. Al-Ktaifani, Enhancement of local plant immunity against tobacco mosaic virus infection after treatment with sulphated-carrageenan from red alga (Hypnea musciformis), Physiol. Mol. Plant Pathol. 84 (2013) 19-27.

[28] E.L. Leite, M.G.L. Medeiros, H.A.O. Rocha, G.G.M. Farias, L.F. Silva, S.F. Chavante, L.D. Abreu, C.P. Dietrich, H.B. Nader, Structure and pharmacological activities of a sulfated xylofucoglucuronan from the alga Spatoglossum schroëderi, Plant Sci. 132 (1998) 215-228.

[29] C. Boisson-Vidal, F. Haroun, M. Ellouali, C. Blondin, A.M. Fischer, A. Agostini, J. Jozefonvicz, Biological activities of polysaccharides from marine algae, Drugs Future 20 (1995) 1237-1249.

[30] F. Haroun-Bouhedja, E. Mostafa, C. Sinquin, C. Boisson-Vidal, Relation between sulfate groups and biological activities of fucans, Thromb. Res. 100 (2000) 453-459.

[31] G.-J. Wu, S.-M. Shiu, M.-C. Hsieh, G.-J. Tsai, Anti-inflammatory activity of a sulfated polysaccharide from the brown alga Sargassum cristaefolium, Food Hydrocolloid 53 (2016) 16-23.

[32] D. Fleita, M. El-Sayed, D. Rifaat, Evaluation of the antioxidant activity of enzymatically-hydrolyzed sulfated polysaccharides extracted from red algae; Pterocladia capillacea, LWT-Food Sci. Technol. 63 (2015) 1236-1244.

[33] Z. Zhang, F. Wang, X. Wang, X. Liu, Y. Hou, Q. Zhang, Extraction of the polysaccharides from five algae and their potential antioxidant activity in vitro, Carbohydr. Polym. 82 (2010) 118-121.

[34] E.M. Balboa, E. Conde, A. Moure, E. Falque, H. Dominguez, In vitro antioxidant properties of crude extracts and compounds from brown algae, Food Chem. 138 (2013) 1764-1785.

[35] A.H. Abou Zeid, E.A. Aboutabl, A.A. Sleem, H.M. El-Rafie, Water soluble polysaccharides extracted from Pterocladia capillacea and Dictyopteris membranacea and their biological activities, Carbohydr. Polym. 113 (2014) 62-66.

[36] H.K. Holme, K. Lindmo, A. Kristiansen, O. Smidsrød, Thermal depolymerization of alginate in the solid state, Carbohydr. Polym. 54 (2003) 431-438.

[37] G. Zhou, Y. Sun, H. Xin, Y. Zhang, Z. Li, Z. Xu, In vivo antitumor and immunomodulation activities of different molecular weight lambda-carrageenans from Chondrus ocellatus, Pharmacol. Res. 50 (2004) 47-53.

[38] C.-Y. Lii, C.-H. Chen, A.-I. Yeh, V.M.-F. Lai, Preliminary study on the degradation kinetics of agarose and carrageenans by ultrasound, Food Hydrocolloid 13 (1999) 477-481.

[39] A. Sarbu, F. Gonçalves, M.N. Pinho, Radical initiated oxidative degradation of oat-spelts xylan, Carbohydr. Polym. 53 (2003) 1-8.

[40] C.M.G.C. Renard, M. Lahaye, M. Mutter, F.G.J. Voragen, J.-F. Thibault, Isolation and structural characterisation of rhamnogalacturonan oligomers generated by controlled acid hydrolysis of sugar-beet pulp, Carbohydr. Res. 305 (1998) $271-280$.

[41] J. Vera, J. Castro, A. Gonzalez, A. Moenne, Seaweed polysaccharides and derived oligosaccharides stimulate defense responses and protection against pathogens in plants, Mar. Drugs 9 (2011) 2514-2525.

[42] R. Ovalle, C.E. Soll, F. Lim, C. Flanagan, T. Rotunda, P.N. Lipke, Systematic analysis of oxidative degradation of polysaccharides using PAGE and HPLC-MS, Carbohydr. Res. 330 (2001) 131-139.

[43] A. Costa, P. Michaud, A. Heyraud, P. Colin-Morel, B. Courtois, J. Courtois, Acetyl substitution of glucuronan influences glucuronan cleavage by GlyA from Sinorhizobium meliloti M5N1CS (NCIMB 40472), Carbohydr. Polym. 51 (2003) 223-228.

[44] T. Sawabe, H. Takahasi, H. Saeki, K. Niwa, H. Aono, Enhanced expression of active recombinant alginate lyase AlyPEEC cloned from a marine bacterium Pseudoalteromonas elyakovii in Escherichia coli by calcium compounds, Enzyme Microb. Tech. 40 (2007) 285-291.

[45] R.M. Rodríguez-Jasso, S.I. Mussatto, L. Sepúlveda, A.T. Agrasar, L. Pastrana, C.N. Aguilar, J.A. Teixeira, Fungal fucoidanase production by solid-state fermentation in a rotating drum bioreactor using algal biomass as substrate, Food Bioprod. Process. 91 (2013) 587-594.

[46] W. Qianqian, M. Shuang, X. Hourong, Z. Min, C. Jingmin, Purification and the secondary structure of fucoidanase from Fusarium sp. LD8. Hindawi Publishing Corporation, Evidence-Based Complement. Altern. Med. 2011 (2011) 8 (Article ID 196190)

[47] V. Descamps, S. Colin, M. Lahaye, M. Jam, C. Richard, P. Potin, T. Barbeyron, J.-C. Yvin, B. Kloareg, Isolation and culture of a marine bacterium degrading the sulfated fucans from marine brown algae, Mar. Biotechnol. 8 (2006) 27-39.

[48] S. Colin, E. Deniaud, M. Jam, V. Descamps, Y. Chevolot, N. Kervarec, J.-C. Yvin, T. Barbeyron, G. Michel, B. Kloareg, Cloning and biochemical characterization of the fucanase FcnA: definition of a novel glycoside hydrolase family specific for sulfated fucans, Glycobiology 16 (11) (2006) 1021-1032.

[49] Z. Yao, F. Wang, Z. Gao, L. Jin, H. Wu, Characterization of K-Carrageenase from marine Cellulophaga lytica strain N5-2 and analysis of its degradation products, Int. J. Mol. Sci. 14 (12) (2013) 24592-24602.

[50] G. Jiao, G. Yu, J. Zhang, H.S. Ewart, Chemical structures and bioactivities of sulfated polysaccharides from marine algae, Mar. Drugs 9 (2011) 196-223.

[51] J.D. Mougous, R.E. Green, S.J. Williams, S.E. Brenner, C.R. Bertozzi, Sulfotransferases and sulfatases in Mycobacteria, Chem. Biol. 9 (2002) 767-776.

[52] P. Manzanares, L.H. Graaff, J. Visser, Characterization of galactosidases from Aspergillus niger: purification of a novel a-galactosidase activity, Enzyme Microb. Tech. 22 (1998) 383-390. 
[53] P.A. Viana, S.T. Rezende, D.L. Falkoski, T.A. Leite, I.C. José, M.A. Moreira, V.M. Guimarães, Hydrolysis of oligosaccharides in soybean products by Debaryomyces hansenii UFV-1 $\alpha$-galactosidases, Food Chem. 103 (2007) 331-337.

[54] M. Cregut, S. Piutti, S. Slezack-Deschaumes, E. Benizri, Compartmentalization and regulation of arylsulfatase activities in Streptomyces sp., Microbacterium $s p$. and Rhodococcus sp. soil isolates in response to inorganic sulfate limitation, Microbiol. Res. 168 (2013) 12-21.

[55] P.C. Jain, J. Lacey, L. Stevens, Use of API-Zym strips and 4-nitrophenyl substrates to detect and quantify hydrolytic enzymes in media and grain colonized with Aspergillus, Eurotium and Penicillium species, Mycol. Res. 95 (7) (1991) 834-842.

[56] M.M.A. El-Gendy, Production of glucoamylase by marine endophytic Aspergillus sp: jAN-25 under optimized solid-state fermentation conditions on agro residues, Aust. J. Basic Appl. Sci. 6 (4) (2012) 41-54

[57] M. Camassola, A.J.P. Dillon, Biological pretreatment of sugar cane bagasse for the production of cellulases and xylanases by Penicillium echinulatum, Ind. Crops Prod. 29 (2009) 642-647.
[58] M. Chen, L. Xia, P. Xue, Enzymatic hydrolysis of corncob and ethanol production from cellulosic hydrolysate, Int. Biodeter. Biodegr. 59 (2007) $85-89$.

[59] C.H. Lee, H.T. Kim, E.J. Yun, A.R. Lee, S.R. Kim, J.-H. Kim, I.-G. Choi, K.H. Kim, A novel agarolytic $\beta$-galactosidase acts on agarooligosaccharides for complete hydrolysis of agarose into monomers, Appl. Environ. Microbiol. 80 (19) (2014) 5965-5973.

[60] A. Miyanaga, T. Koseki, Y. Miwa, Y. Mese, S. Nakamura, A. Kuno, J. Hirabayashi, H. Matsuzawa, T. Wakagi, H. Shoun, S. Fushinobu, The family 42 carbohydrate-binding module of family $54 \alpha$-L-arabinofuranosidase specifically binds the arabinofuranose side chain of hemicelluloses, Biochem. J. 399 (2006) 503-511.

[61] D. Hogg, G. Pell, P. Dupree, F. Goubet, S.M. Martin-Orúe, S. Armand, H.J. Gilbert, The modular architecture of Cellvibrio japonicus mannanases in glycoside hydrolase families 5 and 26 points to differences in their role in mannan degradation, Biochem. J. 371 (2003) 1027-1043. 